\title{
Angkasa Pura Digital Signage pada Bandar udara Syamsudinnor Banjarmasin
}

\author{
${ }^{1}$ Khairul Anwar Hafizd, ${ }^{2}$ Melda Aolia \\ ${ }^{1,2}$ Jurusan Teknik Informatika Politeknik Negeri Tanah Laut \\ ${ }^{1,2}$ Pelaihari, Indonesia \\ E-mail: ${ }^{1}$ Khairul.anwarhafizd@gmail.com, ${ }^{2}$ meldaaolia@ gmail.com
}

\begin{abstract}
Angkasa Pura Digital Signage pada PT Angkasa Pura I (Persero) Bandar udara Syamsudinnor Banjarmasin telah menggunakan aplikasi web dalam penginputan gambar dan video, akan tetapi informasi mengenai jadwal kegiatan masih dilakukan secara manual, yaitu dilakukan secara tertulis. Oleh karena itu perlu dibuat sistem informasi jadwal kegiatan, gambar, video dan kehadiran pegawai menggunakan PHP yang sebelumnya telah dirancang menggunakan ERD, DFD dan Flowchart. Sistem informasi yang telah dibuat ini dapat menginputkan jadwal kegiatan, gambar, video dan kehadiran pegawai yang ditampilkan melalui digital signage atau yang ditampilkan melalui LCD atau layar monitor.
\end{abstract}

Keywords—Papan Pengumuman ( digital signage ), PHP, Sistem Informasi

\section{PENDAHULUAN}

Perkembangan teknologi tidak terlepas dari semakin bertambah majunya teknologi komputer. Kebutuhan akan teknologi komputer semakin diminati oleh perusahaan - perusahaan untuk melakukan pembaharuan khususnya di bidang teknologi informasi. Penggunaan teknologi komputer telah menjadi suatu kebutuhan yang sangat penting bagi kemajuan teknologi informasi, dimana dengan adanya pengembangan teknologi informasi dapat memberikan kemudahan, tepat guna, akurat dan lebih efisien dalam penerapannya. Perusahaan yang menggunakan teknologi informasi salah satunya adalah PT Angkasa Pura I (Persero) Bandar udara Syamsudinnor Banjarmasin.

PT Angkasa Pura I (Persero) Bandar udara Syamsudinnor Banjarmasin, belum mempunyai Kemajuan teknologi dibagian komunikasi salah satunya digital signage. Digital Signage adalah media yang penyampaian pesannya terarah (narrowcast), yang berbeda dari media televisi, yang penyampaian pesannya secara meluas (broascast). Konsep narrowcast inilah yang pada akhirnya akan mempengaruhi bagaimana strategi penyampaian pesan diterapkan pada digital signage. Digital signage ini memanfaatkan teknologi layar datar seperti LCD, LED, atau plasma yang diproyeksikan untuk menampilkan konten multimedia [1]. Informasi yang ditayangkan dengan tampilan menarik akan menjadi nilai tambah ketika informasi tersebut diberikan. Tampilan dari informasi yang disampaikan sangat mempengaruhi kualitas informasi [2]. 
Jurnal INTENSIF, Vol.1 No.2 Agustus 2017

ISSN: 2580-409X (Cetak) / 2549-6824 (Online)

Dengan menggunakan teknologi LCD, atau LED yang semakin hari semakin canggih dan terjangkau, ditambah dengan kemudahan pemakaian, membuat Digital Signage menjadi tren penyampaian informasi di berbagai belahan dunia. Berdasarkan latar belakang permasalahan maka penulis mengangkat judul "Angkasa Pura Digital Signage" Aplikasi ini menggunakan bahasa pemrograman PHP dan MySql sebagai database.

A. Rumusan Masalah

Berdasarkan latar belakang diatas, maka penulis merumuskan masalah yaitu:

1. Bagaimana membangun dan merancang Digital Signage yang dapat digunakan untuk sebuah media penyampaian informasi yang berkontenkan sebuah gambar, video dan teks?

2. Bagaimana Pengujian Digital Signage yang dapat digunakan untuk sebuah media penyampaian informasi yang berkontenkan sebuah gambar, video dan teks?

3. Bagaimana Implementasi Digital Signage yang dapat digunakan untuk sebuah media penyampaian informasi yang berkontenkan sebuah gambar, video dan teks

B. Batasan Masalah

Karena keterbatasan ilmu yang dimiliki penulis, agar tidak terlampau luas dalam pembahasan ini, maka diperlukan batasan masalah sehingga pembahasan dapat terarah dan mencapai tujuan. Batasan batasan masalah tersebut sebagai berikut:

1. Konten yang ditampilkan hanya berupa teks, gambar, video dan tulisan berjalan.

2. Aplikasi hanya berjalan di lokal PT Angkasa Pura I (Persero) Bandar udara Syamsudinnor Banjarmasin

3. Informasi yang digunakan hanya berupa kategori umum saja.

4. Hak akses bagi admin bisa melakukan proses pengelolaan data (memasukkan, mengubah, menghapus, dan melihat) pada semua data

5. Hak akses bagi user hanya bisa melihat konten yang ditampilkan.

C. Tujuan Masalah

Tujuan dibuatnya Angkasa Pura Digital Signage ini adalah sebagai berikut:

1. Merancang dan Membangun Digital Signage sebagai media penyampaian informasi sehingga proses penyampaian informasi bisa lebih cepat dan juga menarik pada PT Angkasa Pura I (Persero) Bandar udara Syamsudinnor Banjarmasin.

2. Membangun Basis Data Digital Signage pada PT Angkasa Pura I (Persero) Bandar udara Syamsudinnor Banjarmasin.

3. Merancang dan Membangun Antarmuka Digital Signage pada PT Angkasa Pura I (Persero) Bandar udara Syamsudinnor Banjarmasin.

4. Mengimplementasikan Digital Signage pada PT Angkasa Pura I (Persero) Bandar udara Syamsudinnor. 
D. Manfaat

Manfaat dibuatnya Angkasa Pura Digital Signage ini adalah sebagai berikut:

1. Mempermudah karyawan mendapatkan informasi.

2. Menghemat biaya dan waktu dalam memberikan informasi

3. Karyawan dapat mengetahui kegiatan-kegiatan apa saja yang dilakukan pada PT Angkasa Pura I (Persero) Bandar udara Syamsudinnor.

\section{METODE PENELITIAN}

A. Metode Pengumpulan Data

1) Metode Wawancara

Metode wawancara merupakan suatu kegiatan yang paling tepat antara seorang sistem analis dengan organisasi atau perusahaan dan merupakan teknik yang paling produktif dalam mencari sebuah informasi. Hal itu dikarenakan wawancara merupakan suatu teknik dimana pencari dan pemberi data dapat langsung bertukar pikiran. Pada metode ini, penulis mewawancarai atau bertukar pikiran dengan pihak yang terkait di Angkasa Pura.

2) Metode Literatur

Dalam melakukan suatu penelitian, diperlukannya suatu metode yang menjadi panduan dasar dalam melakukan penelitian. Pada penelitian ini, metode yang digunakan adalah metode literatur. Metode literatur adalah suatu metode penelitian yang mengumpulkan data dan informasi yang berkaitan dengan penelitian melalui buku, jurnal, internet dan situs-situs internet. Dalam melakukan penelitian penulis mengumpulkan data dan informasi mengenai data karyawan angkasa pura, kemudian sistem, informasi, PHP, dan MySQL untuk mendukung penyelesaian penelitian yang dilakukan.

\section{B. Metode Pengembangan Aplikasi}

Metode pengembangan aplikasi yang digunakan dalam penelitian ini adalah metode Software Development Life Cycle (SDLC) salah satunya yaitu model prototype.

Model prototype (prototyping model) dapat digunakan untuk menyambungkan ketidakpahaman client mengenai hal teknis dan memperjelas spesifikasi kebutuhan yang diinginkan client kepada pengembang perangkat lunak. Sering client membayangkan kebutuhan yang diinginkan tapi tidak terspesifikasikan secara detail dari segi masukan, proses, dan keluaran.

Di sisi lain seorang pengembang aplikasi harus menspesifikasi sebuah kebutuhan secara detail dari segi teknis. Metode prototype dimulai dari mengumpulkan kebutuhan client terhadap aplikasi yang akan dibuat. Kemudian dibuatlah program prototype agar client lebih terbayang dengan apa yang diinginkan. Program ini biasanya menyediakan tampilan dengan simulasi alur perangkat lunak 
sehingga tampak seperti aplikasi yang sudah jadi. Lalu program prototype ini dievaluasi oleh user sampai ditemukan spesifikasi yang diinginkan user.

Tahapan metode prototype disajikan pada Gambar 1.

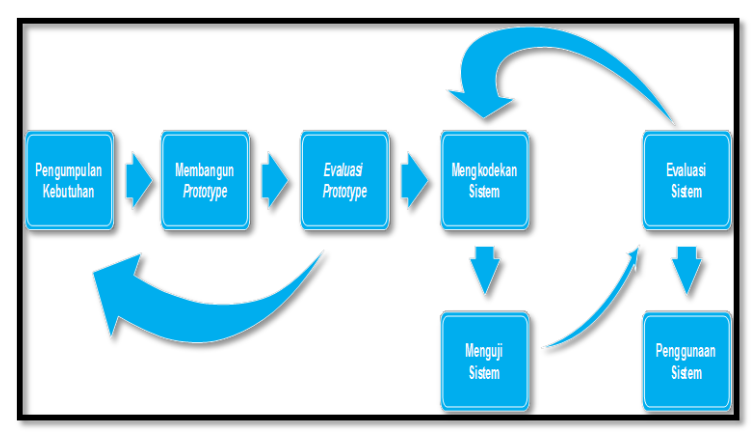

Gambar 1. Metode PROTOTYPE

\section{HASIL DAN PEMBAHASAN}

Angkasa Pura Digital Signage ini dibagi menjadi 2 (dua) tahap, yaitu perancangan dan pengimplementasian sistem.

\section{A. Perancangan Sistem}

Angkasa Pura Digital Signage ini dirancang menggunakan Flowchart, Entity Relationship Diagram (ERD), dan Data Flow Diagram (DFD) meliputi diagram konteks dan dekomposisi.

\section{1) Entity Relationship Diagram (ERD)}

ERD disajikan pada Gambar 2 menggambarkan tabel-tabel yang ada pada basis data Admin dapat mengelola jadwal kegiatan, pegawai dan galeri.

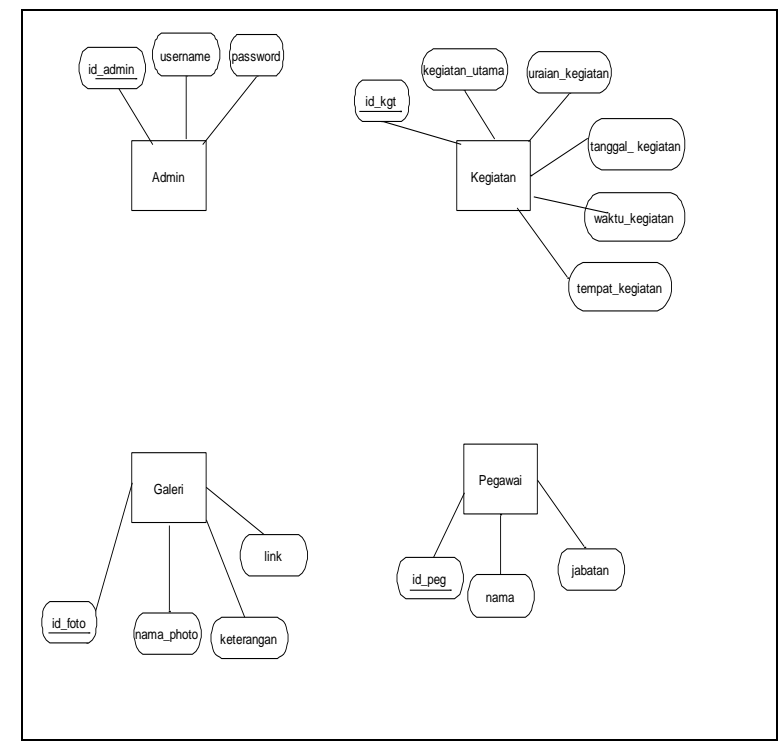

Gambar 2. ENTITY RELATIONSHIP DIAGRAM (ERD) 


\section{2) Diagram Konteks}

Diagram konteks disajikan pada Gambar 3 Sistem informasi ini memiliki dua hak akses yaitu Admin dan User dimana Admin memiliki hak akses untuk memasukkan data kegiatan, galeri dan data kehadiran pegawai sedangkan User hanya memiliki hak untuk melihat kegiatan, galeri dan kehadiran pegawai.

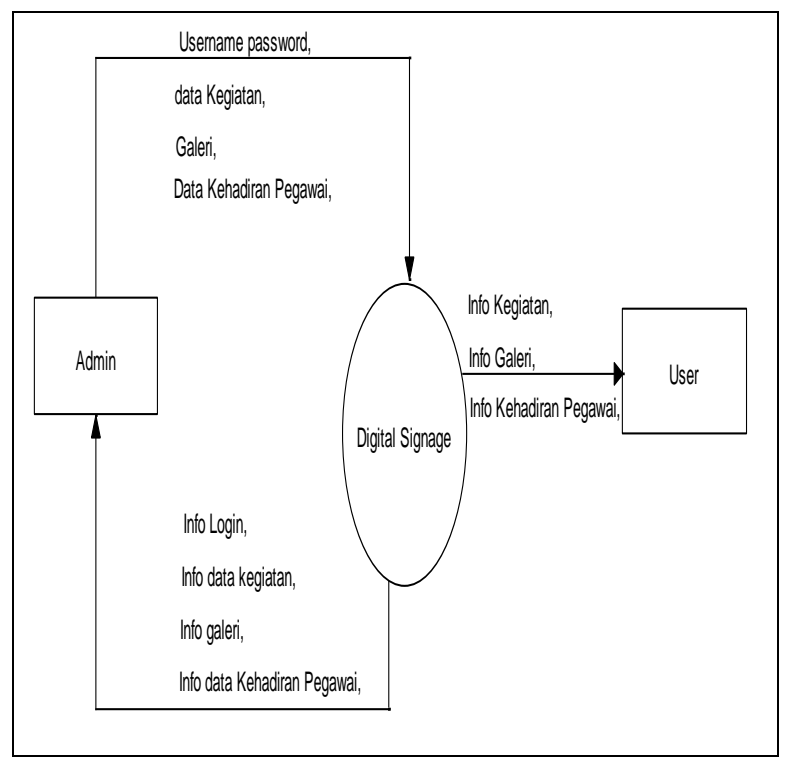

Gambar 3. DIAGRAM KONTEKS

\section{3) Dekomposisi}

Aplikasi ini terdiri dari beberapa sistem, dan setiap sistemnya terdiri dari sub sistem yang hanya Admin yang bisa mengelola setiap sistemnya, user hanya memiliki hak untuk melihat Informasi yang ditampilkan.

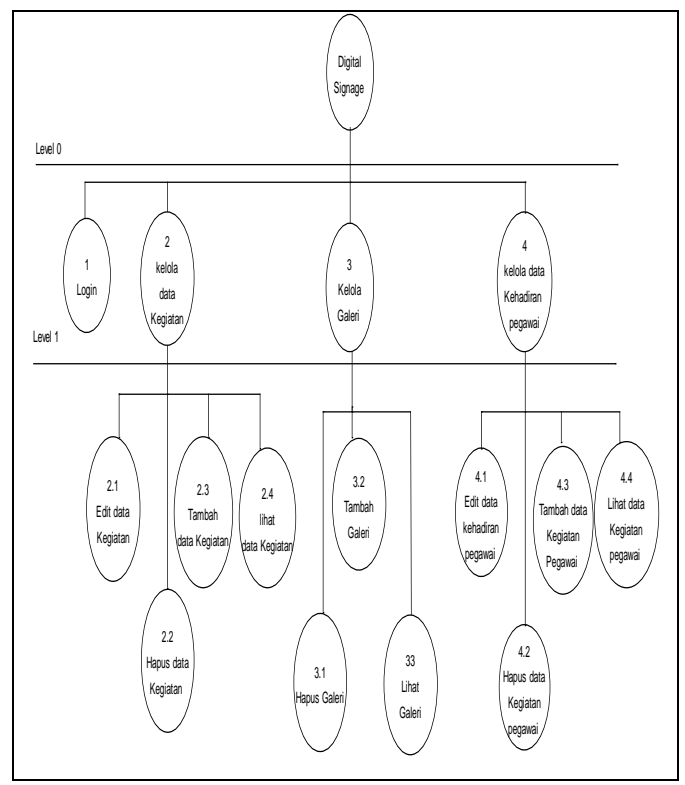

Gambar 4. DEKOMPOSISI 
Pada diagram diatas terdapat Empat (4) proses, yaitu Login, Kelola data Kegiatan, Kelola Galeri, dan Kelola data Kehadiran. Penyimpanan setiap proses berbeda sesuai dengan proses yang dipilih. Admin bertugas mengelola semua proses, dan User hanya dapat melihat info tersebut.

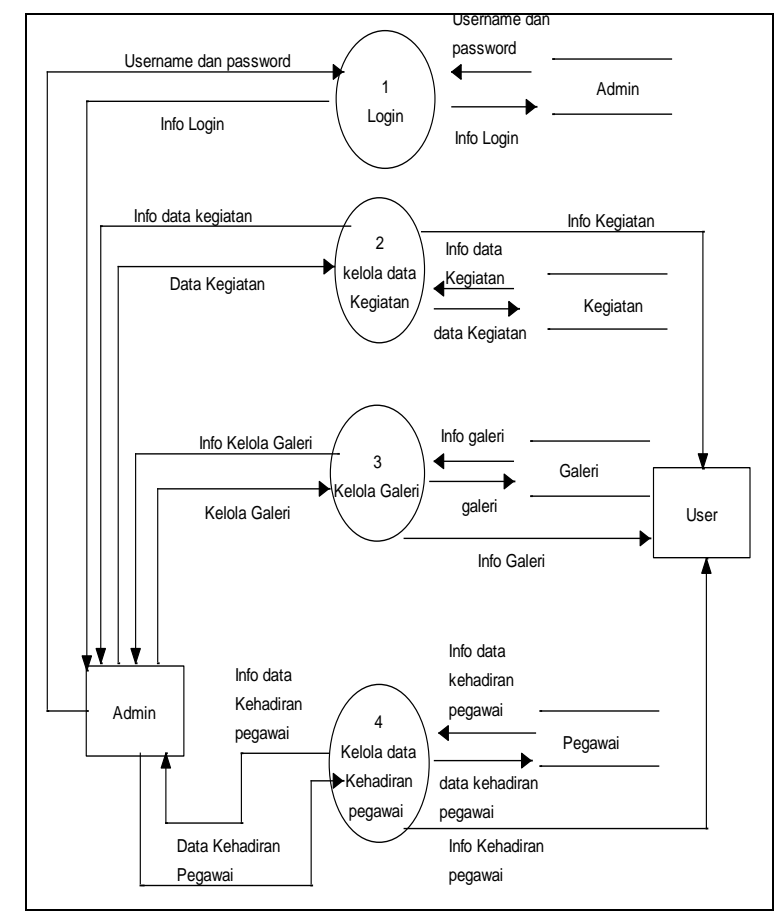

Gambar 5. DATA FLOW DIAGRAM LEVEL 0

\section{5) Data flow diagram level 1 proses 2}

Pada diagram ini dijelaskan bahwa pada proses Kelola Data Kegiatan, Admin dapat melakukan proses edit data, hapus data, tambah data, dan lihat data yang setiap datanya akan dimasukkan atau diperoleh dari database tbl_kegiatan.

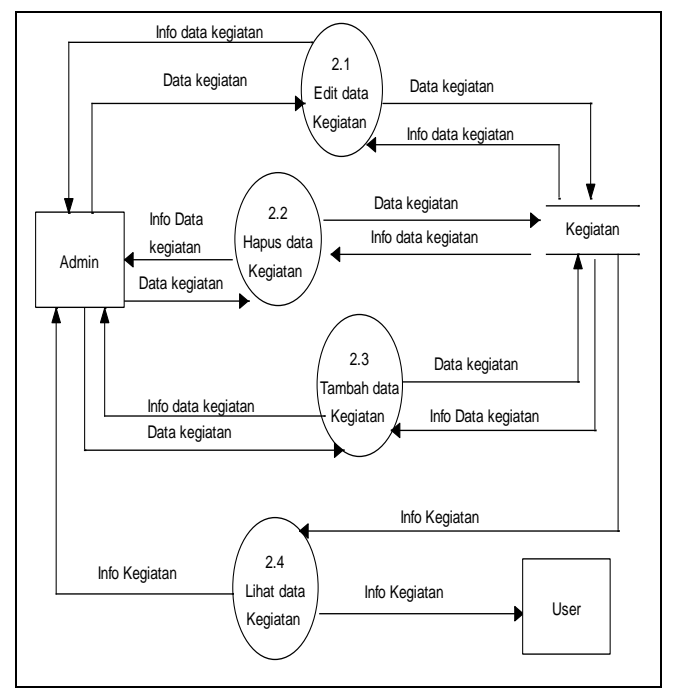

Gambar 6. DATA Flow DiAgRAM LEVEL 1 PROSES 2 


\section{6) Flowchart Login admin}

Pertama Admin masuk ke form Input kemudian proses login dimulai dengan memasukkan username dan password, username dan password akan diidentifikasi terlebih dahulu, apakah username dan password yang dimasukkan username dan password admin jika benar maka akan masuk ke halaman admin jika tidak akan kembali ke form input.

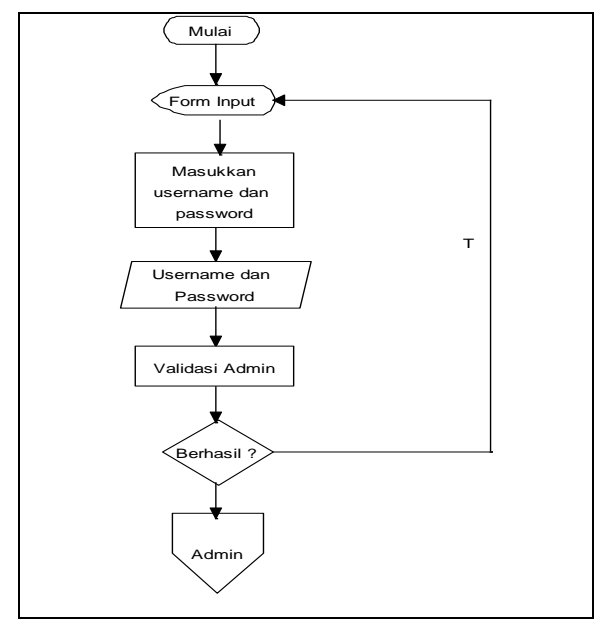

Gambar 7. FLOWCHART LOGIN ADMIN

Ketika telah memasuki form admin maka akan diberikan tampilan seperti Menu utama, form kegiatan, form galeri, form laporan kegiatan, form kehadiran pegawai, dan form tabel pegawai.

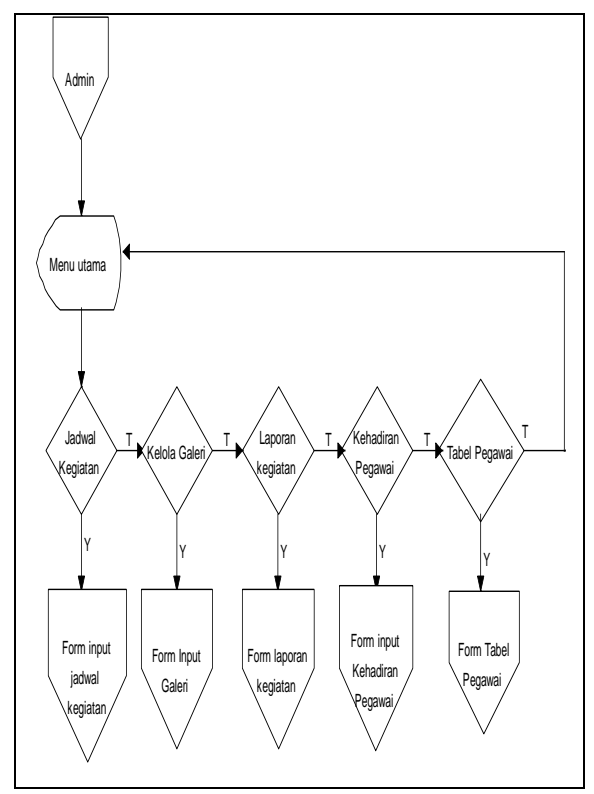

Gambar 8. FlowCHART MENU UTAMA ADMIN 


\section{B. Implementasi Antar Muka}

Rancangan antarmuka yang telah dibuat kemudian diimplementasikan menggunakan PHP.

1) Implemetasi Antar Muka Halaman Login

Implementasi antarmuka halaman login ditunjukkan pada Gambar 9. Halaman ini mengharuskan admin untuk memasukkan username dan password, kemudian mengklik Login untuk masuk ke halaman beranda.

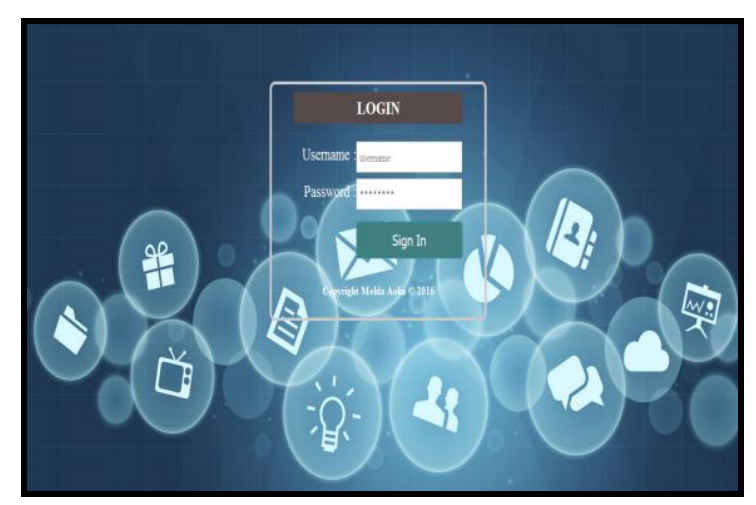

Gambar 9. IMPLEMENTASI ANTARMUKA HALAMAN LOGIN

\section{2) Implemetasi Antar Muka Beranda Admin}

Implementasi antarmuka Beranda Admin ditunjukkan pada Gambar 10. Halaman ini mengharuskan admin untuk Mengelola semua data.

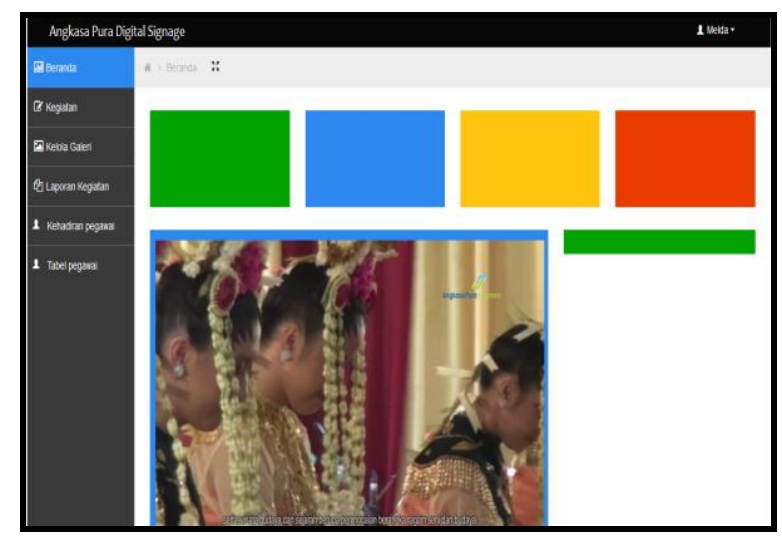

Gambar 10. IMPLEMENTASI ANTARMUKA BERANDA ADMIN 
Jurnal INTENSIF, Vol.1 No.2 Agustus 2017

ISSN: 2580-409X (Cetak) / 2549-6824 (Online)

3) Implementasi Antar Muka Halaman Tambah Jadwal Kegiatan

Penambahan jadwal kegiatan dilakukan dengan mengklik button tambah pada Gambar 10.

Setelah button diklik akan tampil form laporan kegiatan seperti yang ditunjukkan pada Gambar 11.

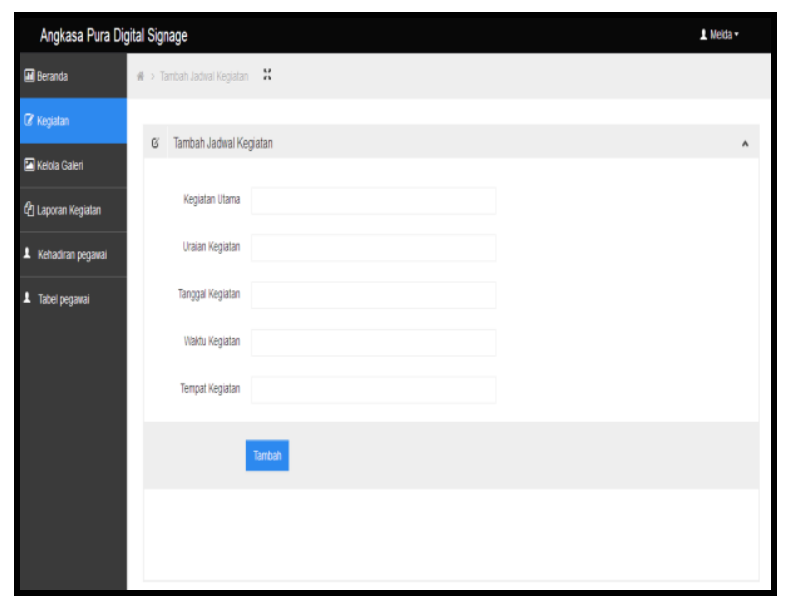

Gambar 11. IMPLEMENTASI ANTARMUKA HALAMAN TAMBAH JADWAL KEGIATAN

4) Implementasi Antar Muka Laporan Jadwal Kegiatan

Implementasi antarmuka laporan jadwal kegiatan ditunjukkan pada Gambar 12. Halaman ini menampilkan jadwal kegiatan yang telah diinputkan.

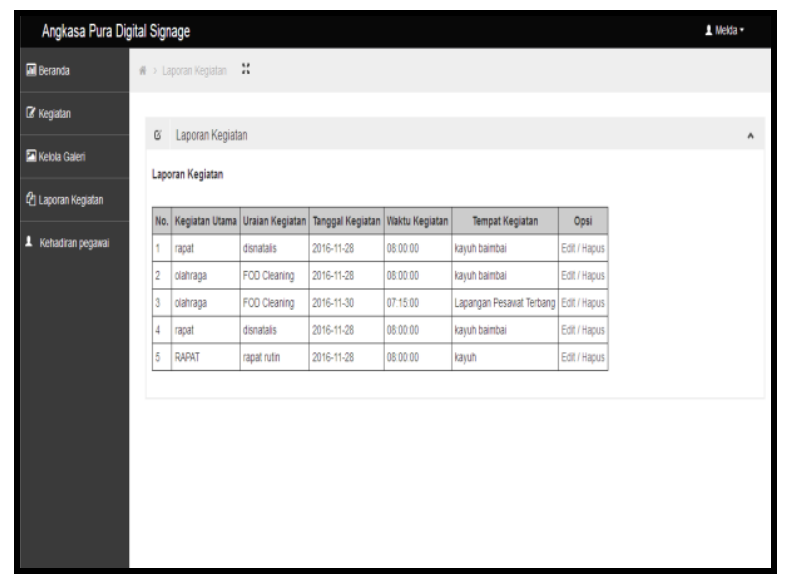

Gambar 12. IMPLEMENTASI ANTAR MUKA LAPORAN JADWAL KEGIATAN.

\section{Implementasi Antar Muka Halaman Galeri}

Penambahan halaman galeri ditunjukkan pada Gambar 13 yaitu dapat menambahkan gambar yang akan ditampilkan dihalaman $u s e r$. 


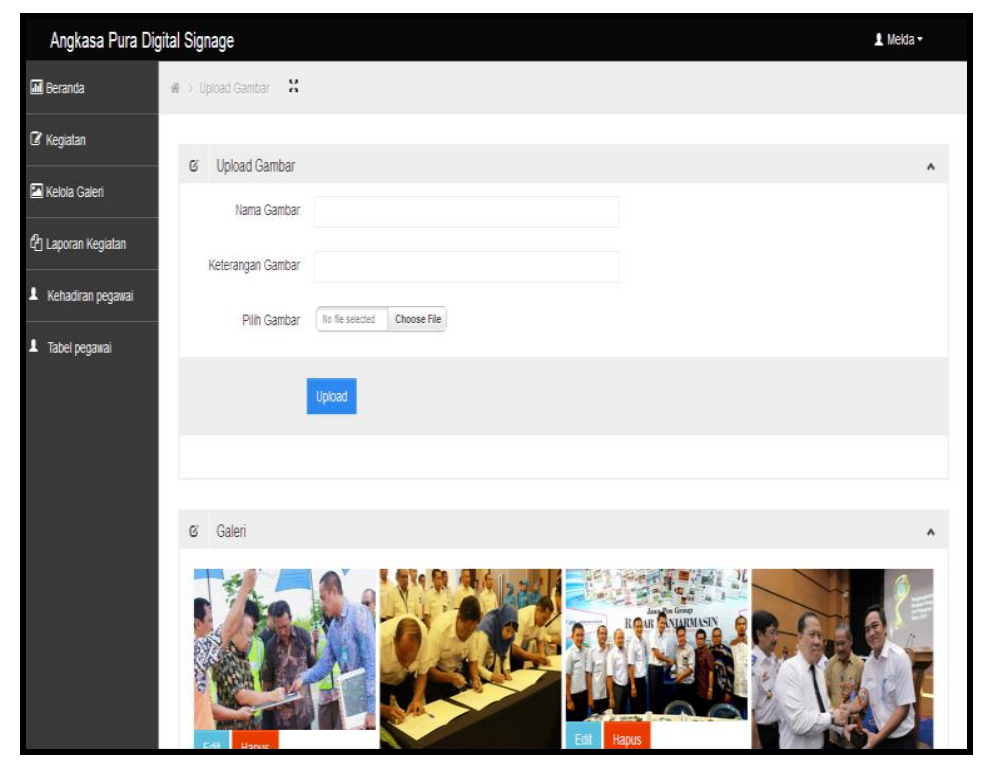

Gambar 13. IMPLEMENTASI ANTAR MUKA HALAMAN GALERI

\section{6) Implementasi Antar Muka Halaman Tambah Kehadiran Pegawai}

Penambahan jadwal kegiatan dilakukan dengan mengklik button tambah pada Gambar 13. Setelah button diklik akan tampil form tabel pegawai seperti yang ditunjukkan pada Gambar 14.

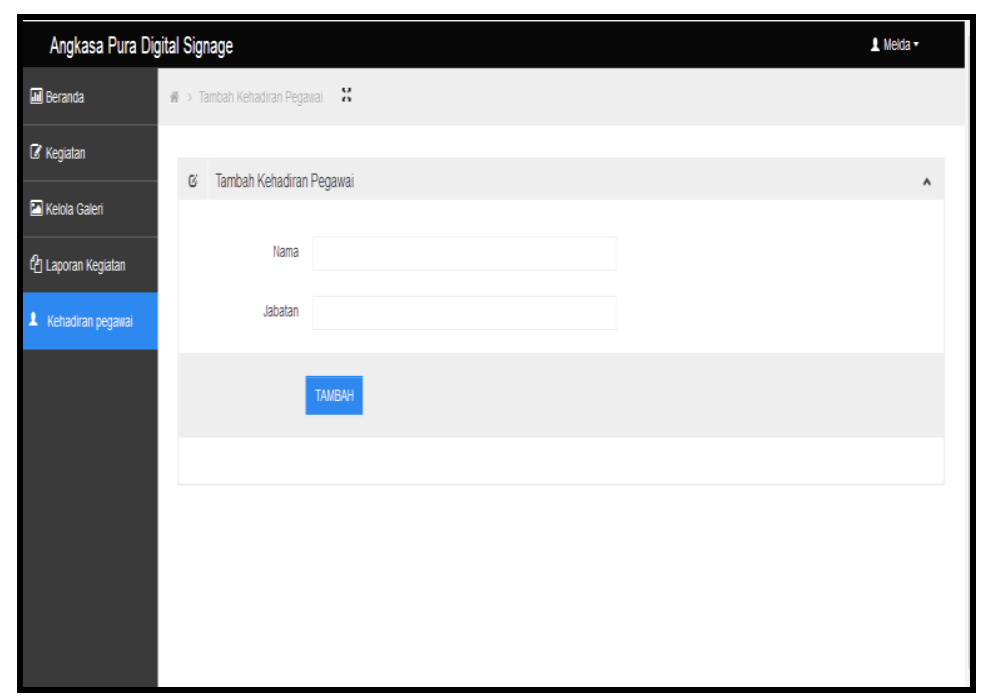

Gambar 14. IMPLEMENTASI ANTAR MUKA HALAMAN TAMBAH KEHADIRAN PEGAWAI 
Jurnal INTENSIF, Vol.1 No.2 Agustus 2017

ISSN: 2580-409X (Cetak) / 2549-6824 (Online)

\section{7) Implementasi Antar Muka Halaman kehadiran Pegawai}

Implementasi antarmuka halaman kehadiran pegawai ditunjukkan pada Gambar 15. Halaman ini menampilkan kehadiran pegawai yang telah diinputkan.

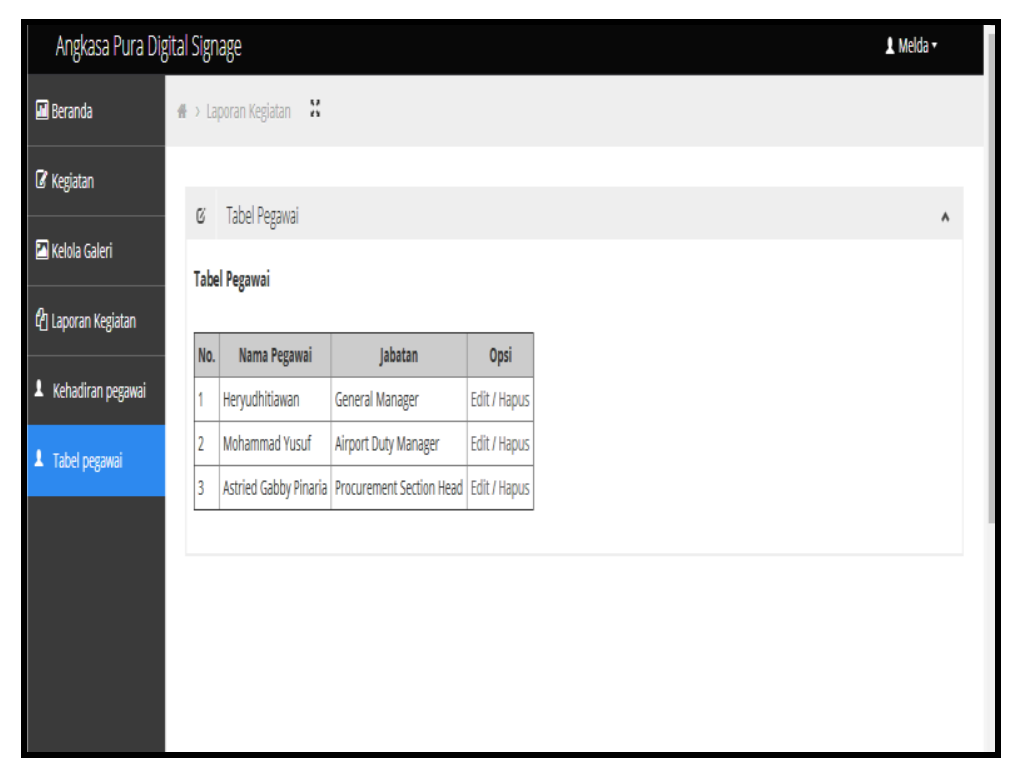

Gambar 15. IMPLEMENTASI ANTAR MUKA HALAMAN KEHADIRAN PEgAWAi

\section{8) Implementasi Antar Muka Halaman User}

Penambahan halaman User ditunjukkan pada Gambar 16 yaitu dapat menampilkan gambar, video, jadwal kegiatan dan laporan kegiatan.

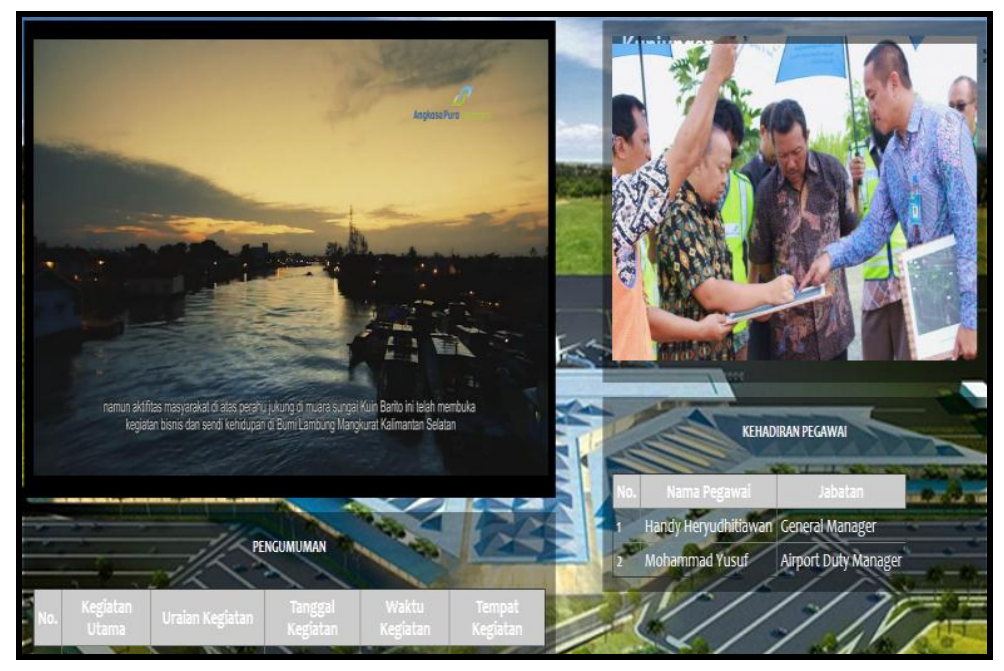

Gambar 16. IMPLEMENTASI ANTAR MUKA HALAMAN USER 


\section{KESIMPULAN DAN SARAN}

Angkasa Pura Digital Signage pada PT Angkasa Pura I (Persero) Bandar udara Syamsudinnor Banjarmasin yang telah dirancang menggunakan ERD, DFD, Flowchart dan dibangun menggunakan PHP ini menyediakan form untuk tambah dan mengelola jadwal kegiatan galeri dan tabel kehadiran pegawai untuk data yang telah ditambahkan.

Untuk pengembangan lebih lanjut maka perlu penambahan fungsi sensor dan fungsi menampilkan jadwal secara otomatis sebagai upaya pengoptimalan aplikasi yang telah dibuat.

\section{Daftar Pustaka}

[1] A. Mulyana and M. Aria, "Perancangan Digital Signage sebagai Papan Informasi Digital Pada Program Studi Teknik Informatika Sistem Komputer Fakultas Teknik dan Ilmu Komputer," Unikom, vol. 13, no. 2, 2015.

[2] R. Panuntun and Dkk, "Perancangan Papan Informasi Digital Berbasis eb pada Raspberry pi Pada Program Studi Teknik Informatika Universitas Diponegoro," J. Teknol. dan Sist. Komput., vol. 3, no. 2, 2015. 